\title{
Review
}

\section{Chronic Myeloid Leukemia}

\section{A Minimalistic View of Post-Therapeutic Monitoring}

\author{
Adam Bagg \\ From the Department of Pathology and Laboratory Medicine, \\ Hospital of the University of Pennsylvania, \\ Philadelphia, Pennsylvania
}

A variety of molecular-based targets are potentially amenable to analysis for the evaluation of minimal residual disease (MRD) following attempts at curative therapies in hematological malignancies. These can be broadly divided into one of three types: pathological rearrangements (translocations), physiological rearrangements (antigen receptor gene rearrangements), and others (for example the overexpression of the Wilm's tumor gene WT1). This review will focus on one specific and extensively studied example from the first group, namely the $t(9 ; 22)$ of chronic myeloid leukemia $(C M L)$. Any appreciation of MRD testing is contingent on an understanding of the biology of the disease being tested, as well as the therapeutic scenario in which it is being tested. Accordingly, this article will also briefly review both the biology and the therapy of $\mathrm{CML}$. The reader is referred to a number of recent reviews that cover other molecular targets available for MRD testing,,$^{1-3}$ as well as to other recent excellent reviews specifically addressing MRD in CML. ${ }^{4-6}$

\section{Disease Biology}

Chronic myeloid leukemia (CML) is a most intriguing disease that has become a challenging paradigm for clinical hematologist-oncologists, experimental biologists, and molecular pathologists. It is a true hematopoietic stem cell disorder that primarily manifests with expanding myelopoiesis. This accounts for the classic peripheral blood features, dominated by the presence of granulocytes in all phases of maturation. It was the first recognized type of leukemia, ${ }^{7}$ and, over a century later, was the first malignancy shown to have an acquired and specific genetic abnormality, with the identification of an abnormally shortened chromosome 22, the Philadelphia $\mathrm{Ph}$ ) chromosome. ${ }^{8}$ Following this seminal discovery, there was a 13 year hiatus before it was demonstrated that the $\mathrm{Ph}$ chromosome resulted from a reciprocal $\mathrm{t}(9$;
22) translocation. ${ }^{9}$ The molecular correlates of this translocation were first identified 10 years later, with the subsequent recognition of the fusion of two distinct genes, $\mathrm{BCR}$ and ABL. ${ }^{10}$ The ability of this chimeric gene and protein to cause $\mathrm{CML}$ was demonstrated by retrovirallytransfecting BCR-ABL into mice in 1990, which led to the induction of a CML-like syndrome. ${ }^{11}$ However, a definitive transgenic mouse model of $\mathrm{CML}$ has remained elusive, despite numerous attempts. There are a variety of mechanisms through which the heightened tyrosine kinase (TK) activity of BCR-ABL transforms cells. A multitude of cellular substrates are phosphorylated by this relocated (from nucleus to cytoplasm) TK, leading to proliferation, diminished growth factor dependence, apoptosis inhibition, and altered adhesion, among other effects. ${ }^{12}$ While the precise subcellular pathways through which these ultimate biological consequences are attained remain to be definitively dissected, the fact that $\mathrm{BCR}-\mathrm{ABL}$ is indeed the cause of CML appears clear now, based on the clinical response to targeted TK inhibition with the drug imatinib mesylate (formerly known as STI571), trade-named Gleevec. ${ }^{13} \mathrm{CML}$ is an at least biphasic disease, with the characteristic chronic phase of the myeloproliferation almost invariably metamorphosing into an acute blastic phase, often through an intermediate accelerated phase. This progression is likely related to the genetic instability induced by BCR-ABL, and is commonly associated with the acquisition of additional, and frequently characteristic, genetic changes. ${ }^{14}$ The $\mathrm{Ph}$ chromosome and BCR-ABL fusion, however, persist through all phases.

The $\mathrm{t}(9 ; 22)$ translocation is not pathognomonic of $\mathrm{CML}$, and may be seen in the context of other leukemias. Although indistinguishable at the traditional karyotypic level, the $\mathrm{t}(9 ; 22)$ translocation comes in three predominant (and a variety of less common) molecular flavors, each with a characteristic (but not completely specific)

Accepted for publication November 20, 2001

Address reprint requests to Dr. Adam Bagg, Director, Hematology, Department of Pathology and Laboratory Medicine, Hospital of the University of Pennsylvania, 7.103 Founders Pavilion, 3400 Spruce Street, Philadelphia, PA 19104-4283. E-mail: adambagg@mail.med.upenn.edu. 


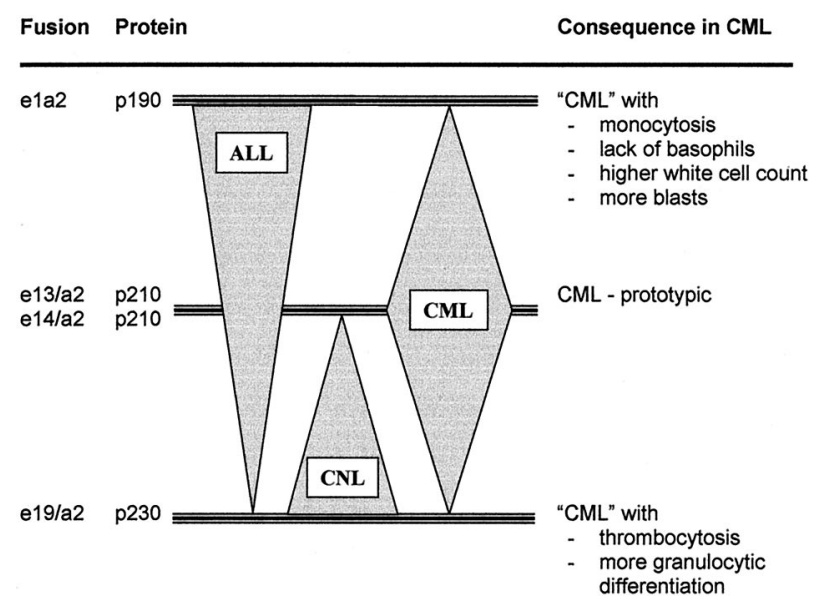

Figure 1. Clinicopathogic correlates of the commonest BCR-ABL fusions. Whereas the p190, p210 and p230 are characteristically associated with adult precursor B-cell, $\mathrm{Ph}+$ acute lymphoblastic leukemia (ALL), chronic myeloid leukemia (CML) and chronic neutrophilic leukemia (CNL), respectively, this association is not absolute. CML with p190 and p230 may be associated with the noted consequences.

clinicopathologic correlate (Figure 1). These differences are due to differences in the breakpoint within the BCR gene. By contrast, breakpoints involving $A B L$ are relatively consistent, typically in the intron before exon 2 (a2). Almost invariably, the breakpoint in $\mathrm{CML}$ involves the Major breakpoint cluster region (M-bcr) of the BCR gene, occurring after exon 13 (e13 or b2) or exon 14 (e14 or b3). These two different breakpoints in the M-bcr are of no established clinical consequence, and although the latter includes an additional $75 \mathrm{bp}$, both give rise to the prototypic, CML-associated p210 protein. By contrast, the p190 protein, generated by a more 5' breakpoint, beyond exon 1 (e1) is more tightly associated with $\mathrm{Ph}+$ acute lymphoblastic leukemia (ALL), while the p230 protein, as a consequence of a more $3^{\prime}$ breakpoint beyond exon 19 (e19), is more characteristically seen in the context of chronic neutrophilic leukemia. Although the involvement of the $\mathrm{M}$-bcr region alluded to above is quite consistently seen in CML, differential or alternative spicing may lead to heterogeneity at the level of the mRNA transcript. This may be minimal, with a single b3a2 DNA fusion yielding both a b3a2 and a b2a2 transcript, or rather more substantial, resulting in an e1a2 transcript. While the latter RNA transcript is characteristically associated with $\mathrm{Ph}+\mathrm{ALL}$, it is commonly seen in CML too. ${ }^{15}$ Importantly, however, it is not a consequence of the $\mathrm{Ph}+$ ALL-associated DNA breakpoint, although it may have some clinicopathologic correlates (see Figure 1) and applications in MRD testing in CML (see below).

\section{Therapeutic Options}

An appreciation of the different therapeutic modalities available for $\mathrm{CML}$ is appropriate for those charged with gauging remission and tracking minimal residual disease post-therapy. CML therapy has undergone numerous changes, and standard therapeutic practice has evolved over the past few decades, most dramatically in the last
10 to 15 years. This has resulted in busulphan supplanting radiotherapy, hydroxyurea supplanting busulphan, and then interferon- $\alpha$ (IFN- $\alpha$ ) supplanting hydroxyurea. However, none of these approaches has led to the eradication of the clone and cure of the disease. The only form of therapy that can currently cure patients of CML, perhaps without complete eradication of the clone, is allogeneic bone marrow or peripheral blood stem cell transplantation (collectively designated SCT in this review). SCT, although the treatment of choice for younger patients, is not trivial, being associated with significant morbidity and mortality, and is not an option for every patient and is not definitively recommended as the treatment of choice for all patients with CML. ${ }^{16}$ The current exciting data notwithstanding, it remains to be determined whether imatinib mesylate (STI571) will become the therapy of choice for this disease. Phase III clinical trials using this agent are currently underway, and other creative therapies, for example, those capable of trapping the BCR-ABL protein in the nucleus, are in the pipeline. ${ }^{17}$ However, even imatinib mesylate may disappoint as a panacea, since CML cells can be quite conniving; reports are emerging of the development of resistance to this form of therapy, with the reactivation of $B C R-A B L$ signal transduction via gene amplification or mutation. ${ }^{18}$

Response to therapy is measured using three broad modalities: hematological, cytogenetic, and molecular. Hematological remission is designated once the blood counts and spleen size have returned to normal, while cytogenetic responses are determined by the percentage of residual $\mathrm{Ph}+$ cells, classified as none (100\%), minor (35 to 99\%), major-partial (1 to 34\%), and majorcomplete $(0 \%) .{ }^{19}$ While these two definitions are simple and reproducible, in the context of contemporary therapy, especially SCT, they have, in large part, been replaced by considerations of molecular remission. A variety of technologies may be included under those used to monitor disease at a molecular level. These include FISH, Southern blot, western blot, and reverse transcriptase polymerase chain reaction (RT-PCR). RT-PCR is performed in preference to DNA PCR, given the fact that the genomic breakpoints are almost invariably intronic and widely dispersed. For example, the breaks in the typically involved first intron of the $\mathrm{ABL}$ gene may occur anywhere within a greater than $300-\mathrm{kb}$ span. While not impossible, ${ }^{20}$ this would render DNA-based analysis rather cumbersome; nature has solved this potential analytic problem for us through the process of mRNA splicing. FISH has some clear applications in certain monitoring scenarios, however none of the first three methods has sufficient analytic sensitivity to consistently detect less than $1 \%$ malignant cells, while RT-PCR is up to four orders of magnitude more sensitive. Accordingly, RT-PCR is the best method for tracking MRD and will be the focus of this review. Nevertheless, even though the discussion will be restricted to $\mathrm{RT}$-PCR, the most powerful and sensitive modality for tracking disease, what will emerge is that this is clearly not straightforward, with much of the complexity a consequence of both rapidly evolving and non-standardized methodologies. This review will attempt to synthesize, reconcile and clarify the published data, and 
highlight the need for the development of international standards. The relative roles of the other modalities, including conventional karyotypic analysis, have recently been reviewed elsewhere. ${ }^{21}$

\section{Minimal Residual Disease Testing}

As alluded to above, MRD testing has different connotations in different therapeutic scenarios. For example, in the context of SCT, approximately 50 to $80 \%$ of patients achieve complete cytogenetic remission, with the majority of those ( $\sim 80$ to $85 \%$ ) also attaining molecular (RT$\mathrm{PCR}$ ) remission. By contrast, while about 30 to $40 \%$ of patients treated with IFN- $\alpha$ reach complete cytogenetic remission, virtually none attain molecular remission. Hence, MRD testing will be considered separately for these two treatment options (as yet, there are no substantive data for imatinib mesylate). While complete eradication of the BCR-ABL clone may not be an absolute prerequisite to the attainment of cure, the degree to which the tumor load is reduced following therapy is a significant prognosticator. Even the most powerful RT-PCR assays are currently unable to exceed a $10^{-8}$ level of sensitivity. However, this level of sensitivity is neither required nor recommended, especially in light of the detection of BCR-ABL transcripts in normal individuals, when tested with this degree of sensitivity. ${ }^{22,23}$ The purported presence of these very low numbers of BCR$\mathrm{ABL}+$ cells in normal individuals is, of course, biologically intriguing. Such findings may then support the notion that BCR-ABL is necessary, but not in isolation, sufficient, for the neoplastic phenotype. Importantly, given that CML at presentation accounts for $\sim 10^{12}$ cells, with these "over-sensitive" assays, this would still leave the order of at least $10^{4}$ cells in the body at the time of "molecular remission". This likely explains why patients in complete molecular remission may relapse. An additional explanation for this is that there are subpopulations, albeit rare, of transcriptionally quiescent cells, ${ }^{24}$ that would be missed by even the most powerful RT-PCR assays. Furthermore, it should be noted that an increase or decrease in BCR-ABL levels does not necessarily correspond to alterations in cell number. In addition to the presence of transcriptionally silent cells noted above, the converse has also been described, wherein cells may up-regulate transcription. ${ }^{25}$

Although RT-PCR is used, and discussed here, primarily in the context of MRD, it may be used in at least three other scenarios. These are: as an up-front diagnostic tool in $\mathrm{Ph}$ chromosome-negative cases, ${ }^{21}$ to predict disease progression, ${ }^{25}$ and in gauging the contamination of autografts. ${ }^{26}$ However, conventional cytogenetics remains the mainstay in the second scenario, and autologous transplantation is fraught with high relapse rates (given the absence of a graft versus leukemia effect), as well as some procedure-related toxicity.

Much of the original literature on MRD testing in CML (published during most of the 1990s) was based on either qualitative PCR (initially) or quantitative, such as competitive PCR, methods (subsequently) that were based on end-point measurements. What has emerged is that a measurement at a single time-point, using a qualitative assay, is not of robust predictive value. Real-time methodology is likely to be associated with a lower variance in the results and a much higher reproducibility rate. Nevertheless, it is appropriate to review the history, albeit brief, of MRD testing to highlight the etiology of some of the apparent confusion and controversy, and set the stage for the grail of more standardized assays. Indeed, as recently as 1999, some noted authorities in this field ${ }^{4}$ proposed that it was difficult to make therapeutic recommendations on MRD studies published to date since there was methodologic heterogeneity at numerous levels. This included different PCR techniques, various levels of sensitivity, and variable and short follow-up. Additionally, it has been argued that there is biological heterogeneity that may confound the efforts to formulate predictive models. Such heterogeneity here includes different kinetics of the tumor in different patients, distinct host-disease interactions-for example, the presence of PR1 (a peptide derived from proteinase 3, an abundant myeloid-restricted enzyme) specific T-cells ${ }^{27}$ —and diverse therapeutic/conditioning approaches. Furthermore, there is the issue (for some) of whether BCR-ABL alone is sufficient for leukemogenesis. However, these proposals were controversial, and spawned quite strong subsequent correspondence from other noted authorities. ${ }^{28-30}$ Similarly, an earlier review ${ }^{31}$ was also associated with a somewhat heterogeneous debate regarding the optimal manner in which to monitor MRD. Albeit historic, in the context of evolving technologies, the reader is referred to this, and the subsequent round table discussion, for some perception of the rather disparate approaches, usually dictated by personal (but substantial) individual experience.

Since the first report of MRD testing in CML in 1989, ${ }^{32}$ there have been numerous studies of various sizes, and with sometimes variable conclusions. This, in large part, reflects the evolution of testing modalities, from purely qualitative assays with parallel but separate dilutional sensitivity controls, through semiquantitative assays using incorporated competitive targets, to real time measurements. Some of the pertinent features from the larger of these studies are summarized in Table 1, specifically reflecting those in the context of the major curative therapeutic modality, SCT. There were concerns in some of the initial studies of the late 1980's and early 1990's regarding the high frequency of false-positive rates, and this prompted efforts at standardization and precautions to prevent contamination early on. ${ }^{33,34}$ Before the advent of real time technology, most attempts at quantitation used dilutional or competitive PCR strategies. Such technology may control for variability in amplification efficiency and reaction kinetics.

\section{Competitive RT-PCR}

In competitive RT-PCR, serial dilutions of an artificially constructed BCR-ABL competitor are added to the patient CDNA, in what is, in essence, a titration assay. ${ }^{35}$ 
Table 1. Major Studies on MRD Testing in CML following Stem Cell Transplantation (SCT)

\begin{tabular}{|c|c|c|c|c|c|c|c|c|c|c|}
\hline \multirow{3}{*}{$\begin{array}{c}\begin{array}{c}\text { Reference } \\
\text { no. }\end{array} \\
36^{\S}\end{array}$} & \multirow{3}{*}{$\frac{n^{*}}{37}$} & \multirow{3}{*}{$\frac{\text { Method }^{+}}{\text {Qual-N }}$} & \multirow{3}{*}{$\begin{array}{c}\text { Sensitivity/cut-off level } \\
10^{-5}\end{array}$} & \multirow{3}{*}{$\begin{array}{c}\begin{array}{c}\text { Median } \\
\text { follow-up }\end{array} \\
\text { 33 }\end{array}$} & \multicolumn{4}{|c|}{ PCR results } & \multirow{2}{*}{\multicolumn{2}{|c|}{$\begin{array}{c}\text { Predictive value of relapse for a } \\
\text { positive PCR result }\end{array}$}} \\
\hline & & & & & \multirow{2}{*}{$\begin{array}{c}+ \\
15\end{array}$} & \multirow{2}{*}{$\begin{array}{r}\text { Relapse } \\
4(27 \%)\end{array}$} & \multirow{2}{*}{$\frac{-}{22}$} & \multirow{2}{*}{$\begin{array}{c}\text { Relapse } \\
0(0 \%)\end{array}$} & & \\
\hline & & & & & & & & & $\begin{array}{l}\text { After } 6 \text { months } \\
\text { Before } 6 \text { months }\end{array}$ & $\begin{array}{l}\text { Yes } \\
\text { No }\end{array}$ \\
\hline 37 & 64 & Qual-N & $10^{-6}$ & $\sim 15$ & 37 & $13(39 \%)$ & 27 & $0(0 \%)$ & $\begin{array}{l}\text { Window } 1 \text { to } 12 \text { months } \\
>1 \text { occasion }\end{array}$ & $\begin{array}{l}\text { Yes } \\
\text { Yes }\end{array}$ \\
\hline 40 & 30 & Qual-N & $10^{-6}$ & $\sim 40$ & 15 & $5(33 \%)$ & 15 & $0(0 \%)$ & $\begin{array}{l}\text { Serial positive } \\
\text { Transient positive }\end{array}$ & $\begin{array}{l}\text { Yes } \\
\text { No }\end{array}$ \\
\hline 39 & 64 & Qual-N & $10^{-6}$ & $\sim 24$ & 33 & $7(21 \%)$ & $31^{\pi}$ & $0(0 \%)$ & No predictive data & \\
\hline 38 & 346 & Qual-N & $10^{-6}$ & $\sim 16$ & $38^{\|}$ & $16(42 \%)$ & $112^{\|}$ & $3(3 \%)$ & $\begin{array}{l}\text { Window } 6 \text { to } 12 \text { months } \\
\text { After } 36 \text { months }\end{array}$ & $\begin{array}{l}\text { Yes } \\
\text { No }\end{array}$ \\
\hline 44 & 52 & Qual-N & 5 cells & $\sim 24$ & 20 & $12(60 \%)$ & 32 & $1(3 \%)$ & $\geq$ One positive result & Yes \\
\hline $42^{\S}$ & 98 & Quant-N & 50 transcripts/ $\mu \mathrm{g}$ RNA & $\sim 16$ & 29 & $21(72 \%)$ & 69 & $1(1 \%)$ & Anytime above cut-off & Yes \\
\hline $43^{\S+\dagger}$ & 138 & Quant-N & $\begin{array}{c}0 \%=- \\
<0.02 \% \text { 㧊 }=\text { low }+ \\
>0.02 \%=\text { high }+\end{array}$ & $\sim 36$ & $\begin{array}{l}63 \text { (high) } \\
14 \text { (low) }\end{array}$ & $\begin{array}{r}52(83 \%) \\
8(57 \%)\end{array}$ & 61 & $14(23 \%)$ & Window 3 to 5 months & Yes \\
\hline 41 & 55 & Qual-N & $10^{-5}$ & $\sim 30$ & $14^{\S \S}$ & $14(100 \%)$ & $41^{\S \S}$ & $0(0 \%)$ & p190 positive & Yes \\
\hline
\end{tabular}

${ }^{*} n$, number of patients enrolled in study.

${ }^{\dagger}$ Qual-N, qualitative, nested; Quant-N, quantitative (using a competitive template; see text for details), nested.

FFollow-up in months. This was measured differently in different studies (from SCT, from first positive PCR result), was sometimes not clearly stated and had to be derived.

${ }^{\S}$ All three of these studies were from the same center (Royal Postgraduate Medical School/Hammersmith Hospital, London).

"The negative PCRs in this study were heterogeneous, being defined as one or more negative PCRs. Some of these negative cases were intermittently PCR positive.

"These PCR data are not for all 346 patients, only for those tested in the window 6 to 12 months post-SCT.

${ }^{* *}$ The relative risk for relapse was 26 , as compared with patients who were PCR negative.

TThe overall relapse rate in this study is quite high, perhaps due to the use of in vivo monoclonal antibody $T$ cell depletion and prolonged immunosuppression.

\#\#This percentage reflects the ratio of BCR-ABL/ABL. 0.02\% BCR-ABL/ABL is equivalent to $100 \mathrm{BCR}-\mathrm{ABL}$ transcripts/ $\mu$ g RNA (see text for details).

$\S \$$ The positive and negative data pertain to p190 positivity only (see text for details).

While the same primers that amplify the patient target also amplify this competitor template, the product sizes are different, so that they may be discriminated from one another in an appropriate electrophoretic system (gel or capillary). A correction factor is then applied to compensate for this size difference, to correct for the more efficient amplification of shorter targets. In the initial studies, visual inspection was used to evaluate the equivalence point at which the sample and competitor products are of equal intensity. More objective tools, such as densitometry or fluorescently- or radioactively-labeled primers, fortunately replaced this approach. A housekeeping transcript, for example ABL or GAPDH, is co-amplified to standardize the results and account for variation in the quantity and quality of the sample, the RNA and the cDNA. Ultimately, results are expressed as a percentage, such as BCR-ABL:ABL, or as numbers of chimeric transcripts per microgram of RNA. One potential pitfall of these assays is that there is no direct control for the RT step, since the competitor is DNA. However, using DNA does have the practical advantage of not needing to deal with RNA degradability.

\section{Stem Cell Transplantation}

Six of the seven studies summarized in Table 1, using purely qualitative nested methodology, and with comparable sensitivities $\left(10^{-5}\right.$ to $\left.10^{-6}\right)$, were able to show, in general terms, the value of RT-PCR in predicting relapse post-SCT. Three of these studies ${ }^{36-38}$ identified time points at which the predictive power was greatest: after 6 months, between the first and twelfth month, and in the window between 6 and 12 months, respectively. From these data, it seems fairly clear that testing too soon after SCT (at least 1 month, probably as long as 6 months) is of no predictive value when using qualitative measurements. The presence of BCR-ABL-positive cells during this time period may reflect the residua of the original clone, but now only in longer-lived and no longer proliferative or clonogenic cells. Alternatively, they may reflect bona fide clonogenic cells that were not pharmacologically obliterated by the conditioning regimen, but have not yet been eradicated by immunological means (graft versus leukemic effect). Only when such cells survive beyond a certain point, typically beyond 6 months, are they likely to reflect resilient clonogenic cells that may ultimately spawn relapse. Allied to this was an important observation ${ }^{38}$ that the predictive power of RT-PCR-positivity was different depending on the source of the SCT. Whereas positivity in the context of related donors predicted relapse, this was not the case in unrelated donors. This highlights the critical role that the immune system (graft versus leukemia) plays in modulating CML.

One reason for the single non-informative study ${ }^{39}$ being non-predictive may be definition-based, in that some of their cases defined as "negative" were intermittently positive. The findings from two studies ${ }^{37,40}$ highlight the importance of serial measurements, with repeated positivity being more predictive than intermittent positivity. In the most recent of these seven qualitative studies, ${ }^{41}$ an intriguing observation was reported. With regard to the kinetics of relapse, there appeared to be a sequential 
pattern of first increasing p210 BCR-ABL transcripts, then increasing myeloid mixed chimerism, and finally increasing p190 BCR-ABL positivity, before cytogenetic and hematological relapse, with p190 BCR-ABL being the most predictive of subsequent relapse. This group proposes using this as a surrogate for quantitative PCR: proposing that if p210 BCR-ABL becomes positive, test for mixed chimerism; if that is positive, test for specific myeloid mixed chimerism; and when that is positive, test for p190 BCR-ABL. However, this study has not been independently confirmed, and it might be premature to recommend the adoption of such a strategy, especially at a time when qualitative PCR studies are poised to become routine.

The two recent studies (both from the same institution) using a more quantitative, competitive RT-PCR approach allowed for the development of actual measurements, rather than the merely positive or negative offered by the qualitative assays. ${ }^{42,43}$ In the first report, ${ }^{42}$ a cut-off of 50 chimeric transcripts/ $\mu \mathrm{g}$ RNA was used. Positivity was defined as $>50$ transcripts/ $\mu \mathrm{g}$ RNA, or increasing values on serial testing, while a negative result was one of undetectable, $<50$ transcripts/ $\mu$ g RNA or decreasing levels on serial testing. The subsequent study used different units, now reporting results as a percentage, based on the ratio of BCR-ABL:ABL. ${ }^{43}$ These data stratified patients into three predictive groups: negative $(0 \%)$, low positive ( $>0 \%$ but $<0.02 \%)$, and high positive $(>0.02 \%)$. Molecular relapse was defined as one of: ratio $>0.02 \%$ on three consecutive occasions at least one month apart, or ratio $>0.05 \%$ on two consecutive occasions, or a rising ratio on three consecutive occasions, with the last two $>0.02 \%$. The cut-off ratio of $0.02 \%$ is reportedly equivalent to 100 transcripts/ $\mu \mathrm{g}$ RNA, twice that used previously. ${ }^{43}$ Additionally, the latter analysis identified a predictive window, somewhat earlier than that noted in the qualitative analyses, with positivity at 3 to 5 months post-SCT being predictive of subsequent relapse.

Whether or not T-cells have been depleted from a SCT graft appears to impact the significance of the RT-PCR results. Whereas RT-PCR positivity was not predictive for relapse in patients treated with unmodified (ie, not T-cell depleted) SCT from unrelated donors, ${ }^{38}$ in a separate study, PCR was clearly predictive in the context of T-cell depleted SCT from unrelated donors. ${ }^{44}$ In this latter study, the presence of one or more positive RT-PCR results was associated with a 56-fold higher risk of relapse, as compared with those patients who were persistently RT-PCR negative.

The usual therapeutic intervention following relapse of CML post-SCT is donor lymphocyte infusion (DLI). The timing of when DLI is given impacts the response to this form of adoptive immunotherapy. ${ }^{45,46}$ Patients treated in molecular (or cytogenetic) relapse responded better to DLI as compared with those treated in overt hematological relapse. This thus highlights one of the practical advantages of molecular monitoring and the benefits of early therapeutic intervention. Interestingly, two apparently distinct patterns of molecular response were observed following DLI. This was either a rapid decline following an initial lag or a more gradual and protracted decrease. This may reflect heterogeneity of the disease or relate to different mechanisms of DLI action. ${ }^{45}$

Importantly, the predictive value of a single positive RT-PCR result is abysmal. From the summation of the data in Table 1, even in those studies in which a positive result was significantly associated with subsequent relapse, it must be emphasized that over one-half of patients who are positive will not relapse. Accordingly, qualitative PCR data, and especially from a single time point, are far too imprecise to be used to make therapeutic decisions in individual patients.

\section{Interferon Therapy}

As noted previously, not all CML patients are eligible for SCT. In this context, IFN- $\alpha$ has been (until the advent of imatinib mesylate) the best option. Unlike SCT, however, it appears that IFN- $\alpha$ cannot, with a few reported exceptions ${ }^{47}$ completely eradicate the clone at the level of RT-PCR, although hematological and cytogenetic remission, and even Southern blot remission, in decreasing order of frequency, may be achieved. In one recent large study, ${ }^{48}$ all 54 patients in complete cytogenetic remission (CCR) remained BCR-ABL positive following therapy, although three patients were intermittently PCR negative. While the median follow up was less than 2 years, some patients followed up for 5 years remained in complete remission, despite persistent PCR-positivity. The median BCR-ABL:ABL ratio at the time of maximal cytogenetic response was $0.045 \%$, and this was used as a cut-off value to determine the predictability of relapse. Thus, $48 \%$ of patients with levels above this relapsed, in contrast to only $4 \%$ of those whose levels fell below this threshold. Looking at their data another way, the median ratio of those who relapsed was $0.49 \%$, and for those who remained in complete remission the median ratio was $0.021 \%(P<0.0001)$. Based on these findings, it has been recommended that once complete cytogenetic remission has been attained, IFN- $\alpha$ should be continued, and RT-PCR performed, until "at least relatively low" levels of residual disease are attained. What this "at least relatively low" level is, remains to be determined, although a $0.021 \%$ level, the median level for those who remained in complete remission, may be appropriate.

In another study of 44 patients, ${ }^{49}$ similar findings were noted; all of the patients, including the 34 patients in CCR, were persistently RT-PCR positive at the time of best karyotypic response. However, there was a clear correlation between the BCR-ABL level and whether the cytogenetic response was complete $(0 \% \mathrm{Ph}+$ cells) or major (1 to $34 \% \mathrm{Ph}+$ cells). The median number of BCR$\mathrm{ABL}$ transcripts in the CCR group was $4 / \mu \mathrm{g}$ RNA, while it was $4490 / \mu \mathrm{g}$ RNA in the major cytogenetic response group. Although not calculated by these authors, these measurements probably correspond to a BCR-ABL:ABL ratio of approximately $<0.001 \%$ and $\sim 1 \%$, respectively. Note that the lower percentage is at least one order of magnitude less than that observed in patients in CCR in the previously referenced study. ${ }^{48}$ While both studies used competitive PCR, in the first study the products 
were quantified using gel electrophoresis following titration while in the latter study the products were analyzed by capillary electrophoresis. An earlier and larger study, on $127 \mathrm{Ph}+\mathrm{CML}$ patients, also clearly stratified responses, with the levels of chimeric transcript correlated with the various levels of cytogenetic response. ${ }^{50}$ Thus, the median BCR-ABL levels, in transcripts/ $\mu \mathrm{g}$ RNA (and BCR-ABL:ABL ratios in parentheses) were 400 (0.04\%), 20,500 (7.1\%), 170,000 (21.0\%), and 430,000 (58.7\%) in cytogenetic complete-, partial-, minor-, and non-responders respectively. Most importantly, the findings in the peripheral blood and bone marrow were equivalent. Accordingly, such measurements may be reliably performed on peripheral blood, perhaps precluding the need for frequent, and more invasive, bone marrow studies.

None of the above studies identified patients who were consistently RT-PCR negative, however another ${ }^{47}$ found quite the opposite. In this analysis, designed to determine the molecular status of $\mathrm{CML}$ patients in prolonged CCR on IFN- $\alpha$, over half of the patients analyzed (10 of 18) became RT-PCR negative. Although these data seem impressive, it is not really appropriate to compare them with those of the other aforementioned studies. ${ }^{48-50}$ In this study, the technology used was different: rather than quantitative, nested competitive methodology, BCR-ABL was measured with in a single, non-nested reaction, followed by hybridization protection assay (HPA) detection. While this methodology is chemiluminescence based, with relative light units measured, it is unclear how these measurements translate into the aforementioned units (for example, number of transcripts/ $\mu \mathrm{g}$ RNA or BCR-ABL: $A B L$ ratio). The sensitivity of this assay is reportedly $10^{-5}$. One distinguishing point of this report ${ }^{47}$ is that patients in very prolonged CCR were specifically studied. Indeed, the median duration of CCR in the 10 negative patients was 42 months - this might explain the differences in these studies, rather than intangible differences in assay methodology and sensitivity. While such data suggest that a point may be reached when IFN- $\alpha$ therapy may be discontinued, these findings await confirmation using more robust quantitative measurements. It remains to be determined whether persistent PCR-negativity correlates with survival, since it is known that clonogenic progenitors may be present, despite the absence of discernible BCR-ABL transcripts. ${ }^{51}$

A potential caveat to the use of RT-PCR alone in monitoring patients post-therapy with IFN- $\alpha$ is that this agent may down-modulate the transcription of BCR-ABL. Accordingly, there are reports in which FISH is positive, and yet RT-PCR, which is around four orders of magnitude more sensitive, may be negative. ${ }^{52}$ Thus, it has been recommended that following the attainment of complete cytogenetic remission, patients be monitored at both the DNA and RNA level. FISH, measuring the former, ought to be used to evaluate for the presence of residual disease, while RT-PCR is also required to predict the risk of relapse. Of interest, this effect of IFN- $\alpha$ on transcription may theoretically be exploited to develop an in vitro sensitivity assay to predict which patients may be resistant to this form of therapy. ${ }^{53}$
In summary, whereas the results of RT-PCR analysis in the context of SCT may potentially be usefully stratified into positive or negative, or above or below a specific cut-off to predict relapse (see Table 1), this currently appears to be less feasible with INF- $\alpha$ therapy. Rather, given that RT-PCR negativity is virtually never attained in this therapeutic context, a range of levels, correlating with different degrees of cytogenetic response, appears to exist. Nevertheless, we should still strive for measurements that are reproducible and precise that may dictate when to intervene therapeutically (for example, when to stop or reintroduce therapy).

\section{Real Time Quantitative-PCR (RQ-PCR)}

It is hoped that some of the confounding factors affecting qualitative and end-point quantitative PCR assays will be circumvented by RQ-PCR analysis. Both ABI Prism7700 (Perkin Elmer, Foster City, CA) and LightCycler (Roche, Mannheim, Germany) ${ }^{54}$ instrumentation have been used, and both Taqman ${ }^{55}$ and FRET detection systems have been evaluated in CML. These systems appear equivalent, although one advantage of the LightCycler is its shorter turnaround time. In addition to providing some much-needed standardization, such methodologies have the advantage of minimizing the risk of contamination, since both amplification and analysis are performed in the same container, as well as improving turnaround time.

Numerous BCR-ABL RQ-PCR studies have been published over the past 3 years, validating and optimizing the procedures, in both diagnostic and monitoring, as well as SCT and IFN- $\alpha$, contexts. This has been performed on both LightCycler ${ }^{56-58}$ and $\mathrm{ABI}$ Prism770059-63 instrumentation. The LightCycler traditionally uses fluorescent resonant energy transfer (FRET) detection technology, but Taqman probes can certainly be used on this instrument too. ${ }^{57}$ From these analyses, it is clear that RQ-PCR results correlate very well with the preceding technologies of conventional cytogenetics, Southern blot analysis, and nested competitive RT-PCR. While the reported sensitivities (ranging from $10^{-4}$ to $10^{-7}$ ) are no better than nested competitive RT-PCR (and indeed may be even lower), this technology offers an opportunity for the much anticipated development of rigorous standards. RQ-PCR is able to discern two- to threefold changes, rather than the, at best, half-log changes attained by nested competitive RT-PCR, and with a broader dynamic range. The strength of the technology lies in the ability to perform the precise, serial measurements required for clinical application.

Different housekeeping mRNA controls have been used, including BCR, ABL, GAPDH, G6PD, PBGD, and $\beta_{2}$-microglobulin. All appear to be acceptable as internal standards. One study, however, showed that both $\beta_{2}$ microglobulin and GAPDH levels are 5 to 10 times higher than $\mathrm{ABL}$ levels. ${ }^{63} \mathrm{ABL}$ has the advantage of using the same Taqman probe, and one of the primers, used to detect the fusion transcript. Since the product sizes generated from RQ-PCR typically have to be smaller than 
those used with previous methodologies, new primers have to be designed. Indeed, one of these RQ-PCR studies $^{60}$ identified a silent polymorphism in BCR exon b2 (e13) that significantly affects the accuracy of quantitation.

Traditional RQ-PCR utilizes recombinant plasmids (for example KW-3 for BCR-ABL) to generate standard curves. An alternative approach, perhaps more palatable to diagnostic clinical laboratories, is to use cell line RNA standards. ${ }^{62}$ This allows one to not only check the efficiency of the reverse transcription step, but also diminishes the dreaded and legitimate concern of contamination when using plasmids.

In contrast to the clinical studies performed using qualitative PCR and semi-quantitative end point PCR, there are as yet no compelling outcome data using RQ-PCR. One study, however, demonstrated the value of this technology in predicting the stage of relapse of the disease. ${ }^{64}$ Here, levels of $0.06 \%, 3.2 \%$, and $21.5 \%$ segregated patients in molecular, cytogenetic, and hematological relapse. However, of some concern, data from the same group, using nested RQ-PCR with Taqman detection on a LightCycler, had CVs that were rather high at 35\%. ${ }^{65}$ Although there appear to be attempts to standardize units of measurement (such as BCR-ABL:ABL ratio, or transcripts/ $\mu \mathrm{g} R \mathrm{RA}$ ), some reports use somewhat confusing units. For example, one group uses a normalized dose (nD) of BCR-ABL, which is expressed as ng of K562 (a BCR-ABL-positive cell line derived from a patient with $\mathrm{CML}$ in blast crisis) total RNA with the same level of BCR-ABL mRNA expression normalized to GAPDH mRNA expression. ${ }^{66}$ In this study, at diagnosis median levels in peripheral blood were $44.3 \mathrm{nD}$ (range, 7.45 to 1880), while in bone marrow the levels were $53.7 \mathrm{nD}$ (range, 7.55 to 3446). While confirming the equivalence of peripheral blood and bone marrow testing, quite striking is the range of BCR-ABL levels between patients, highlighting the significant interpatient heterogeneity. In the context of IFN therapy, a cut-off level of $0.4 \mathrm{nD}$ could discriminate between major or complete cytogenetic response, on the one hand, versus minor or no cytogenetic response on the other.

Based on the report that there is a sequential increase in p210 BCR-ABL transcripts, mixed chimerism and finally p190 BCR-ABL transcripts in relapsing patients, as alluded to earlier, ${ }^{41}$ an alternative approach has been offered. ${ }^{5}$ This recommendation does not require quantitative measurements, but incorporates the above sequential measurements. The requirement to perform lineage-specific (myeloid) mixed chimerism analysis may render this approach too labor intensive for generalized utility. Furthermore, these single institution data need to be confirmed by others.

Most of the above RQ-PCR studies were performed on relatively small numbers of patients, and some were retrospective in design. Their value in validating and optimization of RQ-PCR assays notwithstanding, large, prospective trials with pertinent outcome data are keenly awaited.

\section{Frequency of Monitoring}

Assuming that we are indeed able to standardize methodologic approaches, an additional issue to be resolved in measuring MRD in CML patients is how often to perform these measurements. It has been demonstrated, using competitive nested RT-PCR, that molecular relapse precedes cytogenetic and hematological relapse by a median of 6 months, and sometimes by as long as 13 months following SCT. ${ }^{35}$ Similar observations have been made in the context of IFN- $\alpha .{ }^{67}$

Thus, the European Group of Investigators on $\mathrm{CML}$ (EICML) has published recommendations on the frequency of testing. ${ }^{68}$ Inherent to this is a definition of what constitutes molecular relapse. This group defined RT$\mathrm{PCR}$ relapse as a 10-fold or greater increase in the expression of BCR-ABL, determined by a minimum of three consecutive quantitative PCR analyses. Others have defined molecular relapse as rising or persistently high levels of BCR-ABL (BCR-ABL:ABL ratio of $>0.02 \%$ or $>$ 100 BCR-ABL transcripts/ $\mu \mathrm{g}$ RNA) in two sequential specimens more than 4 months following SCT. ${ }^{42}$ However, the EICML guidelines were published in 1994, before the advent of both sufficient and substantive quantitative studies as well as real time technology. Nevertheless, they do provide a rational framework on which future guidelines, based on contemporary technology, may be built. Following SCT, they recommend that both qualitative and quantitative RT-PCR be performed at 4-week intervals on peripheral blood, for as long as MRD is apparent. The rationale for doing a qualitative assay here is based on its somewhat superior sensitivity. Subsequently, one of three pathways should be followed: 1) if the levels remain constant or decrease, then quantitative monitoring should continue at the same 4-week intervals; 2) if the levels fall below the RT-PCR level of detection, then the interval of testing can increased to every 3 months and performed by qualitative methods and if the assay remains negative for one year, testing may be performed every 6 months to be continued indefinitely; or 3) if the levels increase, then frequent (once weekly) quantitative testing should be instituted.

Once molecular relapse has occurred, as defined above, therapy (likely DLI) should be instituted. For patients transplanted in metamorphosis (accelerated or blastic phase), it has been proposed that molecular monitoring may need to be even more vigilant than every 6 months, perhaps as frequently as every 2 to 3 months. ${ }^{69}$

In the context of IFN- $\alpha$ therapy, the EICML group recommends that once the number of Ph-positive cells has fallen below 10\% (by conventional karyotypic analysis or $\mathrm{FISH}$ ), then quantitative PCR should be performed at 3-month intervals. If the levels are shown to be increasing, then the same pathway as proposed for SCT is to be followed; however, therapy modification would be somewhat different in this context. If the levels are constant or decreasing, quantitative testing should continue at 3-month intervals. 


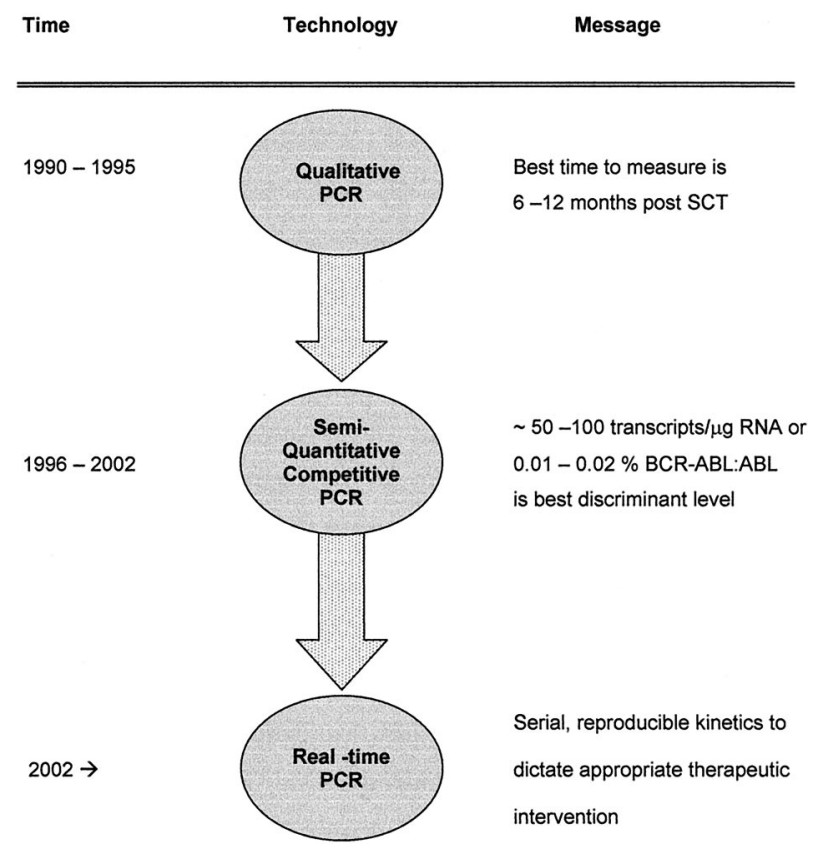

Figure 2. Evolution and impact of MRD testing in CML.

\section{Summary and Conclusion}

As new technology emerges, so paradigms dictating standards of care in MRD testing in CML evolve (Figure 2). Based on the currently published data, the following key points emerge. 1) There are two scenarios in which MRD testing is appropriate in CML: following SCT, to allow for early detection of relapse, and following IFN- $\alpha$, to gauge response. 2) There is a high concordance between peripheral blood and bone marrow testing, indicating that the less-invasive former procedure may suffice in monitoring MRD. 3) A single qualitative (and probably also quantitative) positive RT-PCR result is not predictive of relapse in an individual patient. 4) Most patients are qualitatively RT-PCR positive in the first 6 months following SCT, and this is not of consequence. 5) Patients who are RT-PCR positive after 6 months postSCT are at high risk of relapse. 6) In a relapsing patient, RT-PCR positivity precedes cytogenetic and hematological relapse by several months. 7) Qualitative RT-PCR is of no value in patients being treated with IFN- $\alpha$. 8) For both SCT and IFN- $\alpha$, using quantitative RT-PCR, low or falling levels correlate with continued remission. 9) For both SCT and IFN- $\alpha$, using quantitative RT-PCR, high or rising levels predict relapse. 10) RT-PCR relapse may be reasonably defined as a 10-fold or greater increase in the expression of BCR-ABL, determined by a minimum of three consecutive quantitative PCR analyses. 11) Notwithstanding the different technologies and therapeutic contexts, it appears that the critical level above or below which outcome differs is $\sim 0.02 \%$, which is of the order of $10^{-4}$, and which, interestingly, seems similar to that for other targets in other leukemias and lymphomas. ${ }^{1}$ 12) Since there are, as yet, no large, prospective (but keenly anticipated) RQ-PCR studies evaluating outcome, it is too soon to propose guidelines based on this technology. 13)
Although based on older technology, the EICML frequency of testing recommendations that have been presented are currently appropriate to follow.

However, the key question still remains: can a measured threshold be defined, above which the majority of patients are destined to relapse, and below which the majority of patients can be expected to remain in remission? Although the figure of $\sim 10^{-4}$ appears to prevail, the answer is likely no, given that there is probably a continuum of measurements, with the chances of relapse dictated by other, not currently measured, biological factors, such as PR1-specific T cells. ${ }^{27}$ Moreover, we cannot definitively determine this until we have standardized the following: technology, timing of assay, and units of measurement.

As with any laboratory test used in clinical medicine, we, as molecular pathology practitioners, need to be certain that we offer an assay that is standardized, reproducible, and reliable. Rigorous and regular quality assurance programs are mandatory. Of concern, in the context of both initial diagnosis ${ }^{70}$ and monitoring, ${ }^{71}$ unacceptable interlaboratory variability was evident. In the survey of diagnostic laboratories, using uniform analytes (plasmids and dilutions of a cell line) a rather alarmingly high false positive rate $(10 \%$ and $6 \%$ for the two different substrates, respectively) emerged. In addition to having to grapple with profound issues pertinent to current real time technology, there are always alternative emerging technologies. These include the use of manifold supports to capture mRNA directly from cell lysates, ${ }^{72}$ measuring the fusion transcript in plasma, ${ }^{73}$ and in situ amplification and laser scanning cytometry in individual cells. ${ }^{74}$

In summary, the kinetics of change of the size of the BCR-ABL clone is probably the major determinant in predicting outcome in CML post-therapy, in the context of both SCT and therapy with IFN- $\alpha$, indicating that serial testing is mandatory to allow for rational therapeutic intervention. However, dogmatic guidelines are likely to become redundant, as technology, therapy, and our understanding of the biology of $\mathrm{CML}$, evolves.

\section{Acknowledgments}

I thank Drs. Peter Nowell and David Porter for their kind review of this manuscript and their insightful comments.

\section{References}

1. Bagg A: Minimal residual disease: how low do we go? Mol Diagn 2001, 6:155-160

2. Foroni L, Harrison CJ, Hoffbrand AV, Potter MN: Investigation of minimal residual disease in childhood and adult acute lymphoblastic leukaemia by molecular analysis. Br J Haematol 1999, 105:7-24

3. Campana D, Neale GA, Coustan-Smith E, Pui CH: Detection of minimal residual disease in acute lymphoblastic leukemia: the St. Jude experience. Leukemia 2001, 15:278-279

4. Faderl S, Talpaz M, Kantarjian HM, Estrov Z: Should polymerase chain reaction analysis to detect minimal residual disease in patients with chronic myelogenous leukemia be used in clinical decision making? Blood 1999, 93:2755-2759

5. Roman J, Alvarez MA, Torres A: Molecular basis for therapeutic 
decisions in chronic myeloid leukemia patients after allogeneic bone marrow transplantation. Haematologica 2000, 85:1072-1082

6. Hochhaus A, Weisser A, La Rosee P, Emig M, Muller MC, Saussele S, Reiter A, Kuhn C, Berger U, Hehlmann R, Cross NC: Detection and quantification of residual disease in chronic myelogenous leukemia. Leukemia 2000, 14:998-1005

7. Virchow R: Weisses Blut. Floriep's Notizen 1845, 36:151-156

8. Nowell PC, Hungerford DA: A minute chromosome in human chronic granulocytic leukemia. Science 1960, 132:1497

9. Rowley JD: A new consistent chromosomal abnormality in chronic myelogenous leukemia identified by quinacrine fluorescence and Giemsa staining. Nature 1973, 243:290-293

10. Heisterkamp N, Stephenson JR, Groffen J, Hansen PF, de Klein A, Bartram CR, Grosveld G: Localization of the C-ab1 oncogene adjacent to a translocation break point in chronic myelocytic leukaemia. Nature 1983, 306:239-242

11. Daley GQ, Van Etten RA, Baltimore D: Induction of chronic myelogenous leukemia in mice by the P210bcr/abl gene of the Philadelphia chromosome. Science 1990, 247:824-830

12. Deininger MW, Goldman JM, Melo JV: The molecular biology of chronic myeloid leukemia. Blood 2000, 96:3343-3356

13. Druker BJ, Talpaz M, Resta DJ, Peng B, Buchdunger E, Ford JM, Lydon NB, Kantarjian H, Capdeville R, Ohno-Jones S, Sawyers CL: Efficacy and safety of a specific inhibitor of the BCR-ABL tyrosine kinase in chronic myeloid leukemia. N Engl J Med 2001, 344:10311037

14. Mintzer DA, Bagg A: Clinical syndromes of transformation in clonal hematologic disorders. Am J Med 2001, 111:480-488

15. Lichty BD, Keating A, Callum J, Yee K, Croxford R, Corpus G, Nwachukwu B, Kim P, Guo J, Kamel-Reid S: Expression of p210 and p190 BCR-ABL due to alternative splicing in chronic myelogenous leukaemia. Br J Haematol 1998, 103:711-715

16. Silver RT, Woolf SH, Hehlmann R, Appelbaum FR, Anderson J, Bennett C, Goldman JM, Guilhot F, Kantarjian HM, Lichtin AE, Talpaz M, Tura S: An evidence-based analysis of the effect of busulfan, hydroxyurea, interferon, and allogeneic bone marrow transplantation in treating the chronic phase of chronic myeloid leukemia: developed for the American Society of Hematology. Blood 1999, 94:1517-1536

17. Vigneri $P$, Wang JY: Induction of apoptosis in chronic myelogenous leukemia cells through nuclear entrapment of BCR-ABL tyrosine kinase. Nat Med 2001, 7:228-234

18. Gorre ME, Mohammed M, Ellwood K, Hsu N, Paquette R, Rao PN, Sawyers CL: Clinical resistance to STI-571 cancer therapy caused by BCR-ABL gene mutation or amplification. Science 2001, 293:876-880

19. Talpaz M, Kantarjian H, Kurzrock R, Trujillo JM, Gutterman JU: Interferon-alpha produces sustained cytogenetic responses in chronic myelogenous leukemia: Philadelphia chromosome-positive patients. Ann Intern Med 1991, 114:532-538

20. Waller CF, Dennebaum G, Feldmann C, Lange W: Long-template DNA polymerase chain reaction for the detection of the bcr/abl translocation in patients with chronic myelogenous leukemia. Clin Cancer Res 1999, 5:4146-4151

21. Wang YL, Bagg A, Pear W, Nowell PC, Hess JL: Chronic myelogenous leukemia: laboratory diagnosis and monitoring. Genes Chromosomes Cancer 2001, 32:97-111

22. Biernaux C, Loos M, Sels A, Huez G, Stryckmans P: Detection of major bcr-abl gene expression at a very low level in blood cells of some healthy individuals. Blood 1995, 86:3118-3122

23. Bose S, Deininger M, Gora-Tybor J, Goldman JM, Melo JV: The presence of typical and atypical BCR-ABL fusion genes in leukocytes of normal individuals: biologic significance and implications for the assessment of minimal residual disease. Blood 1998, 92:3362-3367

24. Holyoake $T$, Jiang $X$, Eaves $C$, Eaves A: Isolation of a highly quiescent subpopulation of primitive leukemic cells in chronic myeloid leukemia. Blood 1999, 94:2056-2064

25. Gaiger A, Henn T, Horth E, Geissler K, Mitterbauer G, Maier-Dobersberger T, Greinix H, Mannhalter C, Haas OA, Lechner K: Increase of bcr-abl chimeric mRNA expression in tumor cells of patients with chronic myeloid leukemia precedes disease progression. Blood 1995, 86:2371-2378

26. Corsetti MT, Lerma E, Dejana A, Basta P, Ferrara R, Benvenuto F Vassallo F, Abate M, Piaggio G, Parodi C, Sessarego M, Li Pira G, Manca F, Carella AM: Quantitative competitive reverse transcriptasepolymerase chain reaction for BCR-ABL on Philadelphia-negative leukaphereses allows the selection of low-contaminated peripheral blood progenitor cells for autografting in chronic myelogenous leukemia. Leukemia 1999, 13:999-1008

27. Molldrem JJ, Lee PP, Wang C, Felio K, Kantarjian HM, Champlin RE, Davis MM: Evidence that specific T lymphocytes may participate in the elimination of chronic myelogenous leukemia. Nat Med 2000, 6:1018-1023

28. Goldman JM, Kaeda JS, Cross NC, Hochhaus A, Hehlmann R: Clinical decision making in chronic myeloid leukemia based on polymerase chain reaction analysis of minimal residual disease. Blood 1999, 94:1484-1486

29. Lion T: Monitoring of residual disease in chronic myelogenous leukemia by quantitative polymerase chain reaction and clinical decision making. Blood 1999, 94:1486-1488

30. Moravcova J, Nadvornikova S, Lukasova M, Klamova H: Polymerase chain reaction analyses should be used as a basis for clinical decision making in patients with chronic myelogenous leukemia. Blood 1999, 94:3609-3611

31. Lion $\mathrm{T}$ : Monitoring of residual disease in chronic myelogenous leukemia: methodological approaches and clinical aspects. Leukemia 1996, 10:896-900; 901-906

32. Morgan GJ, Hughes T, Janssen JW, Gow J, Guo AP, Goldman JM, Wiedemann LM, Bartram CR: Polymerase chain reaction for detection of residual leukaemia. Lancet 1989, 1:928-929

33. Hughes T, Janssen JW, Morgan G, Martiat P, Saglio G, Pignon JM, Pignatti FP, Mills K, Keating A, Gluckman E: False-positive results with PCR to detect leukaemia-specific transcript. Lancet 1990, 335:10371038

34. Hughes T, Goldman JM: Improved results with PCR for chronic myeloid leukaemia. Lancet 1990, 336:812

35. Cross NC, Feng L, Chase A, Bungey J, Hughes TP, Goldman JM: Competitive polymerase chain reaction to estimate the number of BCR-ABL transcripts in chronic myeloid leukemia patients after bone marrow transplantation. Blood 1993, 82:1929-1936

36. Hughes TP, Morgan GJ, Martiat P, Goldman JM: Detection of residual leukemia after bone marrow transplant for chronic myeloid leukemia: role of polymerase chain reaction in predicting relapse. Blood 1991, $77: 874-878$

37. Roth MS, Antin JH, Ash R, Terry VH, Gotlieb M, Silver SM, Ginsburg D: Prognostic significance of Philadelphia chromosome-positive cells detected by the polymerase chain reaction after allogeneic bone marrow transplant for chronic myelogenous leukemia. Blood 1992, 79:276-282

38. Radich JP, Gehly G, Gooley T, Bryant E, Clift RA, Collins S, Edmands S, Kirk J, Lee A, Kessler P, Schoch G, Buckner CD, Sullivan KM, Appelbaum FR, Thomas ED: Polymerase chain reaction detection of the BCR-ABL fusion transcript after allogeneic marrow transplantation for chronic myeloid leukemia: results and implications in 346 patients. Blood 1995, 85:2632-2638

39. Miyamura K, Tahara T, Tanimoto M, Morishita Y, Kawashima K, Morishima Y, Saito H, Tsuzuki S, Takeyama K, Kodera Y: Long persistent bcr-abl-positive transcript detected by polymerase chain reaction after marrow transplant for chronic myelogenous leukemia without clinical relapse: a study of 64 patients. Blood 1993, 81:1089-1093

40. Gaiger A, Lion T, Kalhs P, Mitterbauer G, Henn T, Haas O, Fodinger $M$, Kier $P$, Forstinger C, Quehenberger $P$ : Frequent detection of $B C R-A B L$ specific mRNA in patients with chronic myeloid leukemia (CML) following allogeneic and syngeneic bone marrow transplantation (BMT). Leukemia 1993, 7:1766-1772

41. Serrano J, Roman J, Sanchez J, Jimenez A, Castillejo JA, Herrera C, Gonzalez MG, Reina L, Rodriguez MC, Alvarez MA, Maldonado J, Torres A: Molecular analysis of lineage-specific chimerism and minimal residual disease by RT-PCR of p210(BCR-ABL) and p190(BCR-ABL) after allogeneic bone marrow transplantation for chronic myeloid leukemia: increasing mixed myeloid chimerism and p190(BCR-ABL) detection precede cytogenetic relapse. Blood 2000, 95:2659-2665

42. Lin F, van Rhee F, Goldman JM, Cross NC: Kinetics of increasing BCR-ABL transcript numbers in chronic myeloid leukemia patients who relapse after bone marrow transplantation. Blood 1996, 87:44734478

43. Olavarria E, Kanfer E, Szydlo R, Kaeda J, Rezvani K, Cwynarski K, Pocock C, Dazzi F, Craddock C, Apperley JF, Cross NC, Goldman $\mathrm{JM}$ : Early detection of BCR-ABL transcripts by quantitative reverse 
transcriptase-polymerase chain reaction predicts outcome after allogeneic stem cell transplantation for chronic myeloid leukemia. Blood 2001, 97:1560-1565

44. Drobyski WR, Endean DJ, Klein JP, Hessner MJ: Detection of BCR/ $A B L$ RNA transcripts using the polymerase chain reaction is highly predictive for relapse in patients transplanted with unrelated marrow grafts for chronic myelogenous leukaemia. $\mathrm{Br} J$ Haematol 1997, 98:458-466

45. Raanani P, Dazzi F, Sohal J, Szydlo RM, van Rhee F, Reiter A, Lin F, Goldman JM, Cross NC: The rate and kinetics of molecular response to donor leucocyte transfusions in chronic myeloid leukaemia patients treated for relapse after allogeneic bone marrow transplantation. $\mathrm{Br} \mathrm{J}$ Haematol 1997, 99:945-950

46. Formankova R, Honzatkova L, Moravcova J, Sieglova Z, Dvorakova R, Nadvornikova S, Vitek A, Lukasova M, Stary J, Brdicka R: Prediction and reversion of post-transplant relapse in patients with chronic myeloid leukemia using mixed chimerism and residual disease detection and adoptive immunotherapy. Leuk Res 2000, 24:339-347

47. Kurzrock R, Estrov Z, Kantarjian H, Talpaz M: Conversion of interferon-induced, long-term cytogenetic remissions in chronic myelogenous leukemia to polymerase chain reaction negativity. J Clin Oncol 1998, 16:1526-1531

48. Hochhaus A, Reiter A, Saussele S, Reichert A, Emig M, Kaeda J, Schultheis B, Berger U, Shepherd PC, Allan NC, Hehlmann R, Goldman JM, Cross NC: Molecular heterogeneity in complete cytogenetic responders after interferon-alpha therapy for chronic myelogenous leukemia: low levels of minimal residual disease are associated with continuing remission. German CML Study Group and the UK MRC CML Study Group. Blood 2000, 95:62-66

49. Martinelli G, Testoni N, Amabile M, Bonifazi F, De Vivo A, Farabegoli P, Terragna C, Montefusco V, Ottaviani E, Saglio G, Russo D, Baccarani M, Rosti G, Tura S: Quantification of BCR-ABL transcripts in $\mathrm{CML}$ patients in cytogenetic remission after interferon-alpha-based therapy. Bone Marrow Transplant 2000, 25:729-736

50. Hochhaus A, Lin F, Reiter A, Skladny $H$, Mason PJ, van Rhee F, Shepherd PC, Allan NC, Hehlmann R, Goldman JM, Cross NC: Quantification of residual disease in chronic myelogenous leukemia patients on interferon-alpha therapy by competitive polymerase chain reaction. Blood 1996, 87:1549-1555

51. Talpaz M, Estrov Z, Kantarjian H, Ku S, Foteh A, Kurzrock R: Persistence of dormant leukemic progenitors during interferon-induced remission in chronic myelogenous leukemia: analysis by polymerase chain reaction of individual colonies. J Clin Invest 1994, 94:13831389

52. Chomel JC, Brizard F, Veinstein A, Rivet J, Sadoun A, Kitzis A, Guilhot $F$, Brizard A: Persistence of BCR-ABL genomic rearrangement in chronic myeloid leukemia patients in complete and sustained cytogenetic remission after interferon-alpha therapy or allogeneic bone marrow transplantation. Blood 2000, 95:404-408

53. Pane F, Mostarda I, Selleri C, Salzano R, Raiola AM, Luciano L, Saglio G, Rotoli B, Salvatore F: BCR/ABL mRNA and the P210(BCR/ABL) protein are down-modulated by interferon-alpha in chronic myeloid leukemia patients. Blood 1999, 94:2200-2207

54. Wittwer CT, Ririe KM, Andrew RV, David DA, Gundry RA, Balis UJ: The LightCycler: a microvolume multisample fluorimeter with rapid temperature control. Biotechniques 1997, 22:176-181

55. Holland PM, Abramson RD, Watson R, Gelfand DH: Detection of specific polymerase chain reaction product by utilizing the $5^{\prime}-3^{\prime}$ exonuclease activity of Thermus aquaticus DNA polymerase. Proc Natl Acad Sci USA 1991, 88:7276-7280

56. Emig M, Saussele S, Wittor H, Weisser A, Reiter A, Willer A, Berger U, Hehlmann R, Cross NC, Hochhaus A: Accurate and rapid analysis of residual disease in patients with $\mathrm{CML}$ using specific fluorescent hybridization probes for real time quantitative RT-PCR. Leukemia 1999, 13:1825-1832

57. Kreuzer KA, Lass U, Bohn A, Landt O, Schmidt CA: LightCycler technology for the quantitation of bcr/abl fusion transcripts. Cancer Res 1999, 59:3171-3174

58. Bolufer P, Sanz GF, Barragan E, Sanz MA, Cervera J, Lerma E, Senent L, Moreno I, Planelles MD: Rapid quantitative detection of BCR-ABL transcripts in chronic myeloid leukemia patients by realtime reverse transcriptase polymerase-chain reaction using fluorescently labeled probes. Haematologica 2000, 85:1248-1254
59. Mensink E, van de Locht A, Schattenberg A, Linders E, Schaap N, Geurts van Kessel A, De Witte T: Quantitation of minimal residual disease in Philadelphia chromosome-positive chronic myeloid leukaemia patients using real-time quantitative RT-PCR. Br J Haematol 1998, 102:768-774

60. Branford S, Hughes TP, Rudzki Z: Monitoring chronic myeloid leukaemia therapy by real-time quantitative PCR in blood is a reliable alternative to bone marrow cytogenetics. $\mathrm{Br} \mathrm{J}$ Haematol 1999, 107: 587-599

61. Preudhomme C, Revillion F, Merlat A, Hornez L, Roumier C, DuflosGrardel N, Jouet JP, Cosson A, Peyrat JP, Fenaux P: Detection of $\mathrm{BCR}-\mathrm{ABL}$ transcripts in chronic myeloid leukemia $(\mathrm{CML})$ using a "real time" quantitative RT-PCR assay. Leukemia 1999, 13:957-964

62. Saffroy R, Lemoine A, Brezillon P, Frenoy N, Delmas B, Goldschmidt E, Souleau B, Nedellec G, Debuire B: Real-time quantitation of bcrabl transcripts in haematological malignancies. Eur J Haematol 2000 , 65:258-266

63. Amabile M, Giannini B, Testoni N, Montefusco V, Rosti G, Zardini C, Terragna C, Buonamici S, Ottaviani E, Soverini S, Fiacchini M, Bassi S, de Vivo A, Trabacchi E, Saglio G, Pane F, Baccarani M, Tura S, Martinelli G: Real-time quantification of different types of bcr-abl transcript in chronic myeloid leukemia. Haematologica 2001, 86:252-259

64. Elmaagacli AH, Freist A, Hahn M, Opalka B, Seeber S, Schaefer UW, Beelen DW: Estimating the relapse stage in chronic myeloid leukaemia patients after allogeneic stem cell transplantation by the amount of BCR-ABL fusion transcripts detected using a new real-time polymerase chain reaction method. Br J Haematol 2001, 113:1072-1075

65. Elmaagacli AH, Beelen DW, Opalka B, Seeber S, Schaefer UW: The amount of BCR-ABL fusion transcripts detected by the real-time quantitative polymerase chain reaction method in patients with Philadelphia chromosome-positive chronic myeloid leukemia correlates with the disease stage. Ann Hematol 2000, 79:424-431

66. Zanella I, Rossi G, Finazzi D, Capucci A, Albertini A, Cariani E: Quantification of bcr/abl mRNA expression by a rapid real-time reverse transcription-polymerase chain reaction assay in patients with chronic myeloid leukemia. Haematologica 2001, 86:318-319

67. Lion T, Gaiger A, Henn T, Horth E, Haas OA, Geissler K, Gadner H: Use of quantitative polymerase chain reaction to monitor residual disease in chronic myelogenous leukemia during treatment with interferon. Leukemia 1995, 9:1353-1360

68. Lion T: Clinical implications of qualitative and quantitative polymerase chain reaction analysis in the monitoring of patients with chronic myelogenous leukemia: The European Investigators on Chronic Myeloid Leukemia Group. Bone Marrow Transplant 1994, 14:505-509

69. Martinelli G, Montefusco V, Testoni N, Amabile M, Saglio G, Ottaviani E, Terragna C, Bonifazi F, Rosti G, Bandini G, Tura S: Clinical value of quantitative long-term assessment of bcr-abl chimeric transcript in chronic myelogenous leukemia patients after allogeneic bone marrow transplantation. Haematologica 2000, 85:653-658

70. Burmeister T, Maurer J, Aivado M, Elmaagacli AH, Grunebach F, Held KR, Hess G, Hochhaus A, Hoppner W, Lentes KU, Lubbert M, Schafer KL, Schafhausen P, Schmidt CA, Schuler F, Seeger K, Seelig R, Thiede C, Viehmann S, Weber C, Wilhelm S, Christmann A, Clement JH, Ebener U, Enczmann J, Leo R, Schleuning M, Schoch R, Thiel E: Quality assurance in RT-PCR-based BCR/ABL diagnostics: results of an interlaboratory test and a standardization approach. Leukemia 2000, 14:1850-1856

71. Dhingra K, Kurzrock R, Kantarjian H, Baine R, Eastman PS, Ku S, Gutterman JU, Talpaz M: Minimal residual disease in interferontreated chronic myelogenous leukemia: results and pitfalls of analysis based on polymerase chain reaction. Leukemia 1992, 6:754-760

72. Barbany G, Hagberg A, Olsson-Stromberg U, Simonsson B, Syvanen $A C$, Landegren $U$ : Manifold-assisted reverse transcription-PCR with real-time detection for measurement of the BCR-ABL fusion transcript in chronic myeloid leukemia patients. Clin Chem 2000, 46:913-920

73. Silva NH, Pimenta G, Pulcheri WA, Fournier MV, Spector N, da Costa Carvalho MG: Detection of messenger RNA in leukocytes or plasma of patients with chronic myeloid leukemia. Oncol Rep 2001, 8:693-696

74. Pachmann K, Zhao S, Schenk T, Kantarjian H, El-Naggar AK, Siciliano MJ, Guo JQ, Arlinghaus RB, Andreeff M: Expression of bcr-abl mRNA in individual chronic myelogenous leukaemia cells as determined by in situ amplification. Br J Haematol 2001, 112:749-759 